\title{
Médiévales
}

Langues, Textes, Histoire

50 | printemps 2006

Sociétés nordiques en politique ( $\mathrm{XII}{ }^{\mathrm{e}}-\mathrm{XV}^{\mathrm{e}}$ siècles)

\section{Isabelle Lazzarini, L'Italia degli Stati territoriali. Secoli} XIII-XV

Rome, Laterza, 2003 (coll. Quadrante), 199 p.

Didier Boisseuil

\section{(2) OpenEdition}

Journals

Édition électronique

URL : https://journals.openedition.org/medievales/1409

DOI : 10.4000/medievales. 1409

ISSN : $1777-5892$

Éditeur

Presses universitaires de Vincennes

Édition imprimée

Date de publication : 1 juin 2006

Pagination : 179-180

ISBN : 2-84292-186-0

ISSN : 0751-2708

Référence électronique

Didier Boisseuil, «Isabelle Lazzarini, L'Italia degli Stati territoriali. Secoli xII-xv », Médiévales [En ligne], 50 | printemps 2006, mis en ligne le 09 février 2007, consulté le 22 avril 2022. URL : http://

journals.openedition.org/medievales/1409; DOI : https://doi.org/10.4000/medievales.1409

Ce document a été généré automatiquement le 22 avril 2022.

Tous droits réservés 


\title{
Isabelle Lazzarini, L'Italia degli Stati territoriali. Secoli XIII-XV
}

Rome, Laterza, 2003 (coll. Quadrante), 199 p.

\author{
Didier Boisseuil
}

1 Isabella Lazzarini nous livre, à travers ce court ouvrage (doté d'une ample bibliographie) destiné à un public d'étudiants avancés, une réflexion pertinente sur les évolutions politico-institutionnelles de la péninsule italienne entre le milieu du $\mathrm{XIII}^{\mathrm{e}}$ et le milieu du $\mathrm{Xv}^{\mathrm{e}}$ siècle. Elle cherche à mettre en lumière comment des entités politiques très diverses (communes, royaumes, seigneuries) ont évolué et fait place à des formations territoriales plus larges - appelées à la suite de Giorgio Chittolini des «États territoriaux » - dont cinq s'affirment dans la seconde moitié du Quattrocento : les États pontificaux, le royaume de Naples, le duché de Milan, les républiques de Venise et de Florence. Elle se propose de caractériser ces transformations en insistant, d'une part, sur la genèse des structures étatiques, articulées autour d'autorités politiques souveraines (une dynastie, une cité), capables d'assurer l'équilibre entre des pouvoirs autonomes multiples (communautés sujettes); en interprétant, d'autre part, les liens entre les différents États naissants. Car, loin de s'ignorer, ces organismes politiques composites paraissent de plus en plus étroitement liés entre eux, susceptibles de former une véritable koiné à l'intérieur de la péninsule. Il s'agit donc de définir un «système d'États » qui constituent la voie italienne de «l'État moderne », abandonnée à la fin $\mathrm{du} \mathrm{xv}^{\mathrm{e}}$ siècle, suite, essentiellement, au rôle politique nouveau de deux puissances étrangères à l'Italie : les royaumes de France et d'Espagne.

2 Pour détailler son propos, l'auteur adopte un plan simple et efficace en trois parties. Dans un premier temps («les instruments»), l'auteur relate - à la suite de Paolo Cammarosano - l'importance des sources documentaires susceptibles d'éclairer l'histoire de ces États, soulignant les innovations produites par les États de matrice communale (p.1-30), et présente les différentes approches historiographiques sur ce thème depuis Muratori (p. 31-39).

3 Dans une deuxième partie concernant « les structures ", Isabella Lazzarini rappelle les principales configurations politiques de ces États (d'origine monarchique ou 
républicaine) et retrace les rivalités qui les opposent au cours des $\mathrm{XIII}^{\mathrm{e}}-\mathrm{XV}^{\mathrm{e}}$ siècles (p. 48-75). Elle décrit les institutions qui les structurent, indissociables des domaines où s'investit leur action (la guerre, la fiscalité et la justice). Elle s'attarde à souligner le rôle fondamental des offices et de la bureaucratie qui gèrent une partie de l'autorité publique et à définir la variété des configurations territoriales qu'ils fondèrent (p. 75-108). Enfin, elle précise les principaux changements sociaux de la période, dans un contexte de croissance puis de crise, en insistant d'abord sur ce qui constitue les cadres de ces sociétés (les données démographiques et leurs évolutions, les adaptations économiques), en considérant les avatars des structures sociales (comme l'essor de la notion de «sujet» au sein de ces États) et l'une des transformations majeures: «l'institutionnalisation de l'éminence », c'est-à-dire l'apparition d'élites sociales dont la prééminence est créée, confirmée, validée par les institutions étatiques (dans les cours par exemple ou les gouvernements urbains) et reconnue à l'échelle de la péninsule (p. 108-127).

4 Dans une troisième et dernière partie, Isabella Lazzarini aborde, de façon synthétique, «les dynamiques» qui animent ces États. Elle revient sur la notion de «système d'État » qu'elle développe longuement, en rappelant les fondements mêmes de son existence (le nécessaire équilibre entre les différents États péninsulaires et la crainte de la domination étrangère), et en esquissant ses principaux traits : le déploiement d'un ensemble de pratiques diplomatiques complexes et raffinées, la création de structures militaires adaptées (entre autres la formation ou le maintien, à la périphérie de grands ensembles, de petits États confiés à des princes en armes : Gonzague, Montefeltre, etc.), l'intégration des élites laïques et ecclésiastiques, la circulation des hommes et, dans une moindre mesure, des ressources (bien que sur ce point précisément, beaucoup reste à montrer). Elle procède, ensuite, à une analyse comparée des différents États en signalant leurs affinités (les procédures de légitimation des offices par exemple) et leurs divergences (p. 138-160). Pour finir, elle s'interroge sur l'exercice du pouvoir au sein de ces États dont elle définit préalablement la nature. Conçus non pas comme des lieux souverains centrés sur l'autorité du prince ou de son gouvernement (comme l'est idéalement "l'État moderne »), ils apparaissent comme des lieux de médiation et d'organisation politique de forces sociales diverses, capables de garantir la "convivenza» de sujets différents dans des cadres institutionnels variés. Les principaux rapports entre les institutions étatiques, les pouvoirs politiques et les pratiques sociales qui permettent l'essor de ces États sont finement articulés (p. 161-169). Isabella Lazzarini achève son ouvrage en revenant sur les pratiques et les instruments du pouvoir : elle insiste sur le rôle des officiers comme médiateurs entre les différentes forces qui interagissent au sein de l'État et esquisse un aperçu des critiques les plus récentes concernant les approches qu'elle dessine (p. 170-179). 